\title{
Effects of dexamethasone, cyclosporine and betamethasone on inflammatory cell recruitment in mice infected with Strongyloides venezuelensis
}

\begin{abstract}
The objective of this study was verified effect of immunosuppressant activities of Dexametasone (Dexa), Cyclosporine (CsA) and Betamethasone (Beta) in the synhteses of inflammatory cell and dissemination of Strongyloides venezuelensis. S. venezuelensisinfected mice increased total leucocytes (TL), eosinophil (EO), mononuclear cells (MC), and neutrophil (NE) numbers in the blood. The infection induced recruitment of TL, EO and $\mathrm{MC}$ to peritoneal cavity (PCF) and space bronchoalveolar (BALF), exception for NE. Dexa, CsA and Beta treatments inhibited TL, EO and MC production. However, Dexa treatment was associated with NE accumulation in the blood. Dexa and Beta tratments reductions migration of inflammatory cells from the blood to PCF and BALF. Infected mice and treated with Dexa and Beta worm parasites, eggs/g/feces and larvae recovered were higher than CsA. The results showed that glucocorticoid treatment may induce strongyloidiasis dissemination while CsA induced mice protection against $S$. venezuelensis infection.
\end{abstract}

Keywords: strongyloides venezuelensis, dexamethasone, cyclosporine, betamethasone, immunossupression, hyperinfection
Volume 6 Issue 4 - 2019

\author{
Eleuza R Machado, ${ }^{1,2}$ Marlene T Ueta, ${ }^{3}$ \\ Rosângela Maria Rodrigues, ${ }^{4}$ Simone G \\ Ramos, ${ }^{5}$ Virgínia Vilhena, ${ }^{6}$ Anna Maly de Leão \\ e Neves Eduardo, ${ }^{2}$ Leandro Junio Barreto \\ dos Reis, ${ }^{2}$ Raphael da Silva Affonso, ${ }^{2}$ Lúcia \\ Helena Faccioli' \\ 'Department of Clinical,Toxicological and Bromatological \\ Analyzes, Brazil \\ 2Pharmacy Course, Anhanguera College of Brazil, Brazil \\ ${ }^{3}$ Parasitology Department, Brazil \\ ${ }^{4}$ Federal University of Goiás, Brazil \\ ${ }^{5}$ Department of Pathology; Ribeirão Preto Medical School, Brazil \\ ${ }^{6}$ From private practice, Brazil
}

\begin{abstract}
Correspondence: Eleuza Rodrigues Machado, Department of Clinical,Toxicological and Bromatological Analyzes, Ribeirão Preto School of Pharmaceutical Sciences, Ribeirão Preto, University of São Paulo, Brazil, I4,040-903. Tel +55 0163602 4303, Fax +55 01636024725 ,

Email eleuzarodriguesmachado49@gmail.com
\end{abstract}

Received: December 18, 2019 | Published: December 26 2019
Abbreviations: Dexa, dexametasone; Beta, betamethasone; TL, total leucocytes; EO, eosinophil; MC, mononuclear cells; NE, neutrophil, PCF, peritoneal cavity; BALF, space bronchoalveolar

\section{Introduction}

Strongyloidiasis is an intestinal helminthiasis endemic especially in tropical and subtropical areas. ${ }^{1-3}$ It is considered a tropical disease that has been largely ignored. ${ }^{1,4}$ Human infection occurs when infective filariform larvae penetrate the skin. The infection can be asymptomatic, cause chronic infection of the gastrointestinal tract or present a variety of other symptoms, mostly affecting the skin and/or gastrointestinal tract. Many Strongyloides stercoralis infections have been cured. ${ }^{5}$ However, because of the unique ability of S. stercoralis to complete its life cycle within the human host, the quantity of larvae can dramatically increase through a cycle of autoinfection. Autoinfection can thus lead to disease persistence as well as to a syndrome of hyper infection. ${ }^{1}$

The incidence of strongyloidiasis has increased dramatically. Patients presenting altered cellular immunity accompanied by malnutrition; those who have undergone organ or bone marrow transplants; patients with acquired immunodeficiency syndrome as well as those receiving cancer chemotherapy have all been included among those with conditions representing increased levels of infection..$^{6-10}$ In these individuals autoinfection may lead to a massive increase in parasites and dissemination to almost all organs including the lungs, liver and central nervous system. Data from the literature have estimated that disseminated strongyloidiasis occurs in $1.5 \%$ $2.5 \%$ of infected patients, ${ }^{1,5}$ and this disseminated strongyloidiasis can be associated with $86 \%$ death. ${ }^{11}$ These high rates of death should be made about the relative success and failure of drug treatment of patients with chronic strongyloidiasis and developed parasite dissemination.

Cyclosporine has been used almost universally by itself or in combination with other immunossupressory drugs (Dexamethasone and Betamethasone) for the prevention of transplant rejection of the kidney, liver, pancreas, bone marrow, intestine, heart and lungs. ${ }^{11-13}$ The number of patients who have received these drugs increased still more, as they became accepted as a therapeutic strategy in the treatment of auto-immune diseases including rheumatoid arthritis, psoriasis, líquem plan, pemphigus bolhoso, multiple sclerosis, lupus erithematosus, myasthenia Gravis, diabetes mellitus, uveitis and several glomerulonefrits. ${ }^{14-17}$ 
Researchers have suggested that corticoid therapy (glucocorticoids) interfers with the metabolism of steroids in the parasites, producing increases in fertility and the production of eggs. In the case that the females are in the intestinal mucous membrane the result is large numbers of infective larvae which can develop and disseminate throughout the organism. ${ }^{18}$ The mechanisms involved in this process, however, are as yet unknown. The elevated reproduction of adult females is correlated with an inhibition of the immune cellular and humoral response induced by corticoids acting and this immunossupresion improve parasite repoduction. Corticoides drugs may act not only on females inducing reproduction and growth hormones (ecdysteroids), but also favoring an increase in fertility and dissemination within the host. The objective of this study was to compare the immunosuppressor activity of Dexametasone, Cyclosporine and Betamethasone in the inflammatory cell responses and in the maintenance of infection by Strongyloides venezuelensisinfected mice.

\section{Materials and methods}

\section{Animals}

Male Balb/c mice weighing 16-25g (and aged 21-30days) and male Rattus norvegicus (Wistar) rats weighing 120-180g were obtained from the Faculdade de Ciências Farmacêuticas of the Universidade de São Paulo in Ribeirão Preto (FCFRP-USP). All experiments were approved by and conducted in accordance with guidelines established by the Animal Care Committee (Protocol in the 02.1.1408.53.8) of the FCFRP-USP. All animals were maintained under standard laboratory conditions.

\section{Parasites}

The $S$. venezuelensis L-2 strain (Brumpt, 1934), ${ }^{19}$ was isolated from the wild rodent Bolomys lasiurus in April, 1986. The Rattus norvergicus Wistar, are routinely maintained and experimentally infected in the Laboratory of Immunology of FCFRP-USP, São Paulo, Brasil.

Infection of mice with $S$. venezuelensis and treatment with Dexamethasone, Cyclosporine and Betamethasone S. venezuelensis third-stage infective larvae (L3) were obtained from charcoal cultures of infected rat feces. The cultures were stored at $28^{\circ} \mathrm{C}$ for 72 hours, and the infective larvae were collected and concentrated using a Baermann apparatus. The recovered larvae were washed several times in phosphate buffer solution (PBS) and counted. The number was subsequently adjusted to $15.000 \mathrm{~L}^{3}$ per $\mathrm{mL}$ of $\mathrm{PBS}$ for infection. $\mathrm{Balb} / \mathrm{c}$ mice were individually inoculated via s.c abdominal injection with $100 \mu \mathrm{L}$ of PBS containing $1.500 \mathrm{~S}$. venezuelensis L3. The infected mice were divided into four groups: Group 1 was treated orally by gavage with $100 \mu \mathrm{L}$ of water. The animals of Group 2 were treated via s.c with $100 \mu \mathrm{L}$ of Dexamethasone disodium phosphate (Decadron ${ }^{\circledR}$, Aché Laboratories, Campinas, Brazil, $2 \mathrm{mg} \mathrm{kg}^{-1}$ ), Group 3 animals were treated orally by gavage with $100 \mu \mathrm{L}$ of Cyclosporine (Sandimmun Neoral ${ }^{\circledR}$, Novartis, $2.5 \mathrm{mg} \mathrm{kg}^{-1}$ ), and Group 4 was treated via s.c with $100 \mu \mathrm{L}$ of Betamethasone disodium phosphate (Celestone ${ }^{\circledR}$, Aché Laboratories, Campinas, Brazil, $2 \mathrm{mg} \mathrm{kg}^{-1}$ ). The first treatment for three drugs used, beginning one hour before infection and then daily until day 37 (final evaluation day). The last treatment was applied one hour before sacrificing, according to the literature. ${ }^{20}$ Additionally a control group of uninfected, untreated mice enabled comparisons with the infected groups that received treatments or not.

\section{Collection of blood, serum, bronchoalveolar lavage fluid (BALF), and peritoneal cavity fluid (PCF)}

On days $1,3,5,7,14$, and 21, post-infection, the mice were anaesthetized via subcutaneous injection of $30 \mathrm{mg} / \mathrm{kg}$ of tribromoethanol (Acros Organics, Fairlawn, NJ, USA) and blood samples were collected by cardiac puncture. The mice were subsequently sacrificed using an overdose of tribromoethanol. The chest cavity of each animal was carefully opened, the trachea exposed and catheterized. The catheter was tied in place, and sterile PBS/sodium citrate $(0.5 \%)$ was infused in three $1-\mathrm{mL}$ aliquots. The BALF was collected and stored on ice. The PCF was obtained by injecting three $\mathrm{mL}$ of PBS into the peritoneal cavity. Total cell counts of the blood, BALF, and PCF were immediately taken in a Neubauer chamber. Differential counts were obtained using Rosenfeld-stained cytospin preparations or smears. ${ }^{20}$ Blood was then centrifuged, and the serum stored at $-70^{\circ} \mathrm{C}$.

\section{Infective larvae, eggs, and adult worm counts}

On days 1, 3, 5, 7, 14 and 21, post-infection, mice infected with $S$. venezuelensis were placed individually on clean, moist absorbent paper and allowed to defecate. The Cornell-McMaster eggcounting technique was used to determine the eggs/g of feces. ${ }^{21}$ The parasitological examination was performed twice with the average of the two results recorded. The mice were then sacrificed using an overdose of tribromoethanol. To count the adult parasites $10-\mathrm{cm}$ duodenal sections were removed, placed in Petri dishes containing saline, longitudinally sectioned, and incubated for two hours at $37^{\circ} \mathrm{C}$. The lungs were retrieved and compressed so that migrating larvae could be collected and counted. ${ }^{20}$ The adult parasites from the intestines, larvae in the lungs, as well as the eggs from feces, were counted under a light microscope (40 or $100 \times$ magnification).

\section{Statistical analysis}

Each experiment was performed twice. The results of the experiments are expressed as mean \pm SEM. Statistical variations were analyzed using ANOVA followed by the Bonferroni test. The Student's t-test was used only in the analysis of parasite and egg numbers. The level of statistical significance was set at $\mathrm{P}<0.05$.

\section{Results}

Dexamethasone, Betamethasone, and Cyclosporine are associated with parasite burdens, adult worms and fertility of $S$. venezuelensisinfected mice.

Figure 1 demonstrates that $S$. venezuelensis-infected mice treated with dexamethasone (Dexa), cyclosporine (CsA), or betamethasone (Beta) improve retention of the adult female parasites in the host and these parasites numbers increased significantly the period of parasitism (Figure 1A). Among the mice treated with Dexa or Beta, the adult female parasite numbers remained throughout the period of infection. The period of retention of the parasites induced by the CsA treatment, however, was smaller than for the other treatments, being detected only until 14 days post-infection. The numbers of adult parasites recovered of intestine in the $5^{\text {th }}$ and $7^{\text {th }}$ days post-infection were respectively: $107 \%$ and $37 \%$ for the Dexa treatment, $29 \%$ and $21 \%$ for the Beta treatment, and $42 \%$ and $18 \%$ for CsA. These numbers were higher than observed in the infected and untreated group. For the mice of the untreated group the adult parasites were completely eliminated between the $7^{\text {th }}$ and $14^{\text {th }}$ day post-infection. 
Among the infected mice treated with Dexa and Beta, parasitism was observed on the fourteenth and twenty-first days, the maximum period analyzed (Figure 1A). The longest incidence of permanence of the parasites in the mice was identified to be among the female parasites in the duodena and larvae in the lungs, as demonstrated in Table 1.

The eggs of the parasites, excreted by the infected mice, were fertile. In the feces of the mice treated with Dexa and Beta (Figure 1B) eggs were observed with larvae on the fifth day post-infection. The percentage of infective larvae in the feces cultures of the fifth and seventh days post-infection following treatment with Dexa, CsA, or Beta, when compared with the control group, were: $14 \%$ and $92 \%$, $4 \%$ and $32 \%, 8 \%$ and $12 \%$, respectively. The female adult parasite remained fertile in all periods analyzed. The larvae forms recovered from lungs during all phases of the parasitism were significantly higher in the mice treated with Dexa and Beta (Table 1).
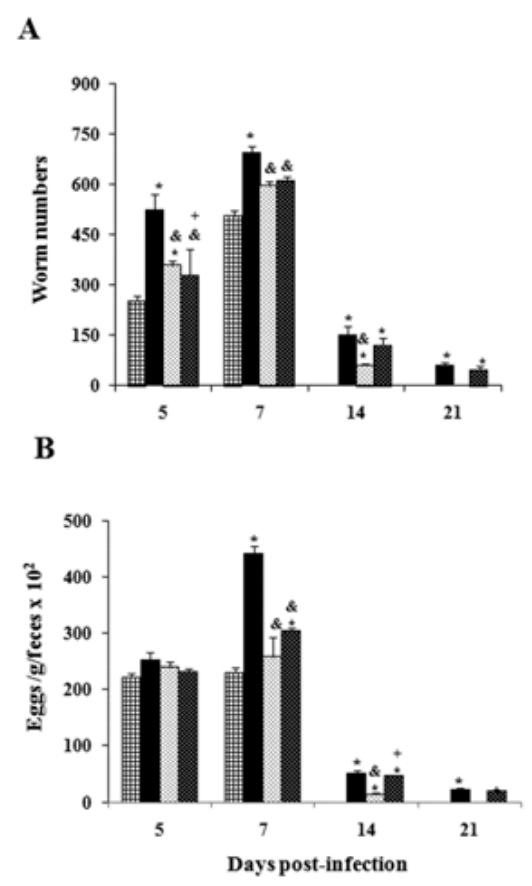

Figure I Number of worm parasites (A) and eggs per gram feces; (B) recovered from mice infected with $S$.

venezuelensis (Sv) larvae cultured for 3 days at $28^{\circ} \mathrm{C}$ and treated or untreated daily per s.c. with Dexa, dexamethasone; CsA, cyclosporine; Beta betamethasone. A group of uninfected mice was used as a control. Data are expressed as the mean \pm SEM from 2 independent experiments $(n=6-10 /$ day), uninfected animals ( $n=6-7 /$ day). Statistical comparisons were made within each particular day of infection. ${ }^{*}, \mathrm{~S} v+\mathrm{H}_{2} \mathrm{O}$ vs. $\mathrm{Sv}+\mathrm{Dexa}, \mathrm{Sv}+\mathrm{Cs} A$, or Sv+Beta;\&Sv+Dexa;+CsA; $\phi S v+$ Beta. *\&+P<0.05.

The Effects of Dexamethasone, Cyclosporine and Betamethasone on the inflammatory leucocyte influx in the blood of mice infected with $S$. venezuelensis Figure 2 shows qualitative and quantitative increases of total leucocytes in the blood in response to the infective larvae of $S$. venezuelensis, and the effects of Dexa, CsA and Beta in the treatment of the infected mice. In contrast mice to the control group infected with infective larvae of S. venezuelensis cultivated during three days at $28^{\circ} \mathrm{C}$, induced an increase in the total leucocytes (Figure 2A), neutrophils (Figure 3), eosinophils (Figure 4A), and mononuclear cells (Figure 4D) in the blood between the first and twenty-first days post-infection. The total leucocyte, neutrophil, eosinophil, and mononuclear cells numbers varied during the course of infection. Two peaks of total leucocytes were observed: with increases in eosinophil and neutrophil numbers on the fourteenth day (Figure 2A, 3, 4A\&4D), and with increasing mononuclear cells on the twenty-first day post-infection (Figure 4D).

Table I The effect of Dexa, dexamethasone; CsA, cyclosporine; Beta, betamethasone on the number of infective larvae recovered from the lungs during S.venezuelensis (Sv) infection

\begin{tabular}{|c|c|c|c|c|}
\hline Post-infection & $\mathrm{Sv}+\mathrm{H}_{2} \mathrm{O}$ & Sv + Dexa & Sv + CsA & Sv + Beta \\
\hline Days & Lungs & Lungs & Lungs & Lungs \\
\hline I & $25 \pm 4$ & $190 \pm 7 *$ & $148 \pm 19 *$ & $152 \pm 6 *$ \\
\hline 3 & $17 \pm 2$ & $72 \pm 6^{*}$ & $15 \pm 2$ & $78 \pm 7^{*}$ \\
\hline 5 & $\ldots$ & $29 \pm 7^{*}$ & $10 \pm 1 *$ & $32 \pm 7^{*}$ \\
\hline 7 & $\ldots$ & $10 \pm I^{*}$ & $10 \pm 2 *$ & $10 \pm 2 *$ \\
\hline 14 & $\ldots$ & $\mid I \pm I^{*}$ & $\ldots$ & $9 \pm 1 *$ \\
\hline 21 & $\ldots$ & $10 \pm 1 *$ & $\ldots$ & $7 \pm 1^{*}$ \\
\hline
\end{tabular}

Lungs were obtained on post-infection days I, 3, 5, 7, I4, and 21 . To evaluate the number of infective larvae, the lungs were tweezed in saline and maintained for $2 \mathrm{~h}$ at $37^{\circ} \mathrm{C}$. Following centrifugation, the pellet was examined under a light microscope at $40 \times$ magnifications for the detection of parasites. Data are expressed as the mean \pm SEM from 2 independent experiments $(n=6-10 /$ day). *, $\mathrm{S} v+\mathrm{H}_{2} \mathrm{O}$ vs. either $\mathrm{S}_{v}+\mathrm{Dexa}$ or $\mathrm{S}_{v}+\mathrm{CsA} .{ }^{*} \mathrm{P}<0.05$.

The total leucocyte values found in the blood of mice treated with Dexa, CsA and Beta were similar or lower when compared to control mice, throughout the period of analysis (Figure 2A). Dexa, CsA and Beta treatments appear to have significantly inhibited eosinophil and mononuclear cell numbers in the blood (Figure 4A\&D). This inhibition, however, was more notable when mice were treated with Dexa and Beta. Nevertheless, CsA and Beta treatments, do not appear to have interfered with the neutrophil numbers in the blood on any of the days after infection. Blood neutrophilia increased over time in the blood of mice treated with Dexa as demonstrated on the fourteenth and twenty-first days post-infection (Figure 3).

Effects of Dexamethasone, Cyclosporine, and Betamethasone on the inflammatory leucocyte influx in the peritoneal cavity and BALF Infective larvae of $\mathrm{S}$. venezuelensis induced in mice increased the infiltrate of total leucocytes (Figure 2B), eosinophils (Figure 4B) and mononuclear cells (Figure 4E) in the peritoneal cavity, when compared with the control mice, for all days analyzed. Quantitative variation was observed in the total leucocyte numbers, eosinophils and mononuclear cells during the infection. The migration of inflammatory cells to the peritoneal cavity was time-dependent. The peak in the total leucocytes 
(Figure 2B) and mononuclear cells (Figure 4E) were observed on the fourteenth day and in eosinophils (Figure 4B).on the twenty-first day post-infection in mice infected and untreated.

A
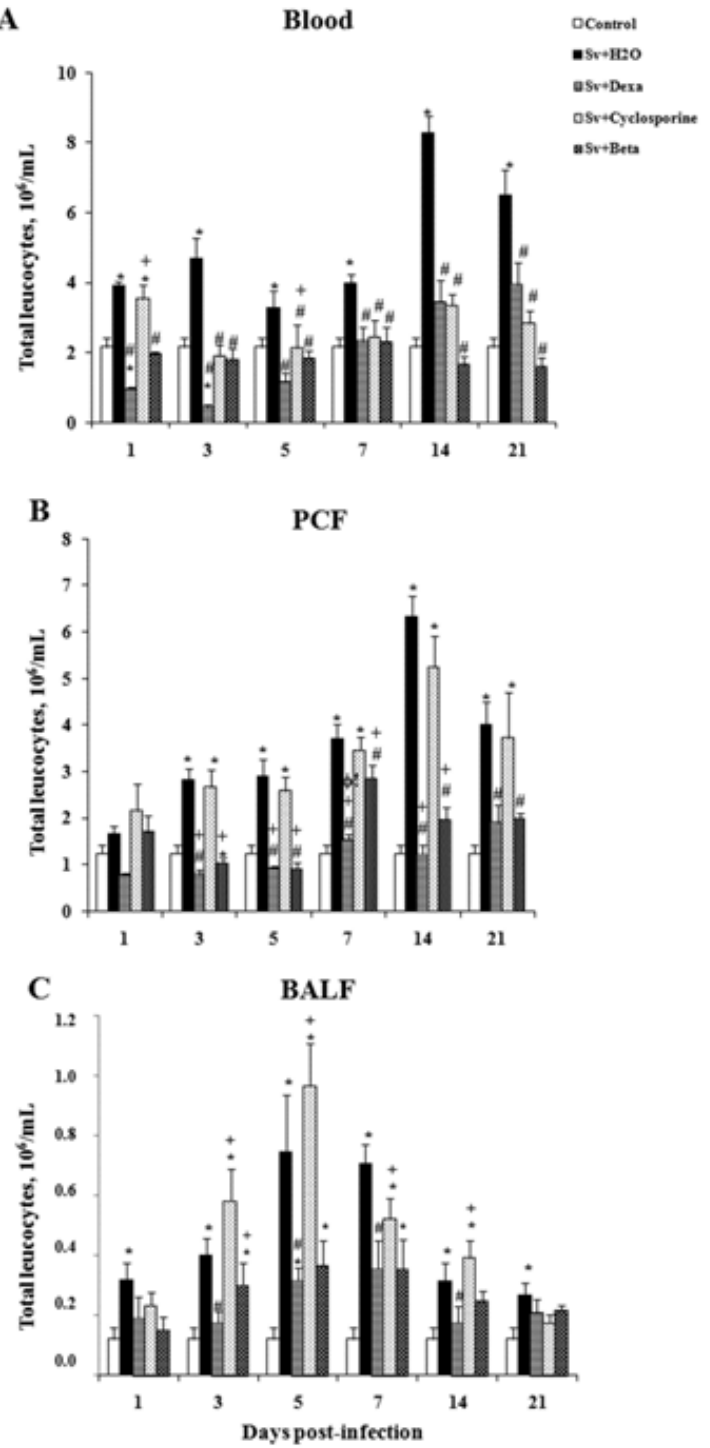

Figure 2 Number of total leukocytes found in blood (A), PCF (B), and BALF (C) in mice infected with $S$.

venezuelensis (Sv) larvae cultured for 3 days at $28^{\circ} \mathrm{C}$ and treated or untreated daily per s.c. with Dexa, dexamethasone; CsA, cyclosporine; Beta, betamethasone. A group of uninfected mice was used as a control. Data are expressed as the mean \pm SEM from 2 independent experiments $(n=6-10 /$ day , uninfected animals $(n=6-7 /$ day). Statistical comparisons were made within each particular day of infection.*, Controls vs. $\mathrm{Sv}+\mathrm{H}_{2} \mathrm{O}, \mathrm{Sv}+\mathrm{Dexa}, \mathrm{Sv}+\mathrm{CsA}$, or $\mathrm{Sv}+$ Beta; $\# \mathrm{~S}+\mathrm{H}_{2} \mathrm{O},{ }^{\mathrm{Q}} \mathrm{S} v+$ Dexa; $+\mathrm{CsA} ; \phi \mathrm{Sv}+$ Beta. ${ }^{*} \&+\phi \mathrm{P}<0.05$.

The Dexa and Beta treatments of infected mice were associated with an inhibition in the recruitment of total leucocytes, eosinophils and mononuclear cells in all periods when compared with mice of the infected and untreated group. These cell numbers were similar or lower than those detected in the control mice during the infection and treatment (Figure 2B, 4B\&E). It appeared that the CsA treatment caused a decline in recruitment of the total leucocytes, eosinophils and mononuclear cells to peritoneal cavity, when compared with the infected and untreated mice. Still, the values observed in these cells were significantly higher when compared with the control group.
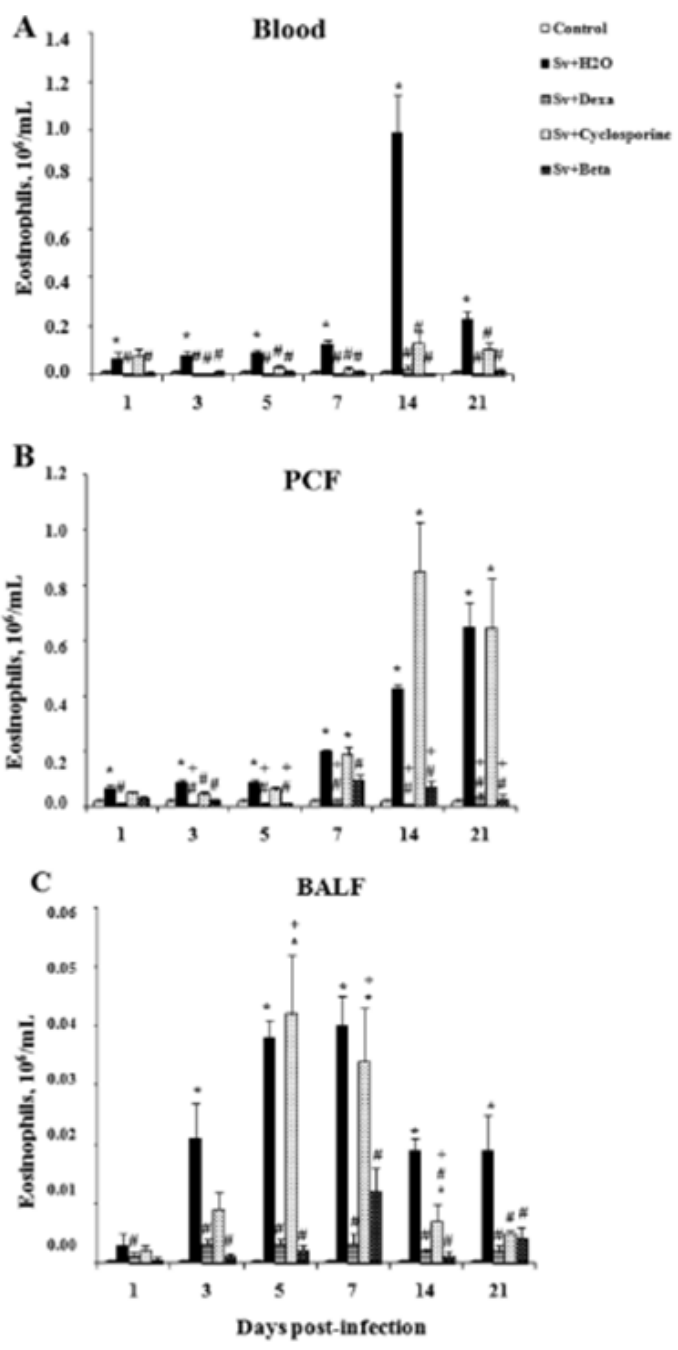

Figure 3 Number of neutrophils found in the blood of mice infected with S. venezuelensis ( $\mathrm{Sv}$ ) larvae cultured for 3 days at $28^{\circ} \mathrm{C}$ and treated or untreated daily per s.c. with Dexa, dexamethasone; CsA, cyclosporine; Beta, betamethasone.A group of uninfected animals was used as a control. Data are expressed as the mean $\pm S E M$ of the neutrophil numbers from 2 independent experiments with infected mice $(n=6-10 /$ day) and uninfected animals $(n=6-$ 7/day). Statistical comparisons were made within each particular day of infection. *, Controls vs. $\mathrm{Sv}+\mathrm{H}_{2} \mathrm{O}, \mathrm{Sv}+\mathrm{Dexa}, \mathrm{Sv}+\mathrm{CsA}$, or $\mathrm{S} v+\mathrm{Beta} ;{ }^{\#} \mathrm{~S} v+\mathrm{H}_{2} \mathrm{O}$, ${ }^{\circledR}$ Sv+Dexa;+CsA; ${ }^{\dagger}$ Sv+Beta. ${ }^{*}{ }^{*}+\phi<0.05$.

Figures $2 \mathrm{C}, 4 \mathrm{C}$ and $4 \mathrm{~F}$ demonstrate that infective larvae of $\mathrm{S}$. venezuelensis also induced significant recruitment of total leucocytes, eosinophils and mononuclear cells in the BALF, when compared with control mice. The peaks of total leucocytes and eosinophils in the infected and untreated mice were detected on the seventh day and for mononuclear cells on the fifth day post-infection. The Dexa treatment appeared to decrease the influx of total leucocytes, eosinophils and mononuclear cells to the lungs when compared with the infected and untreated mice (Figure 2C, 4C\&F), but the values found to those cells were similar or equal when compared with control mice. 

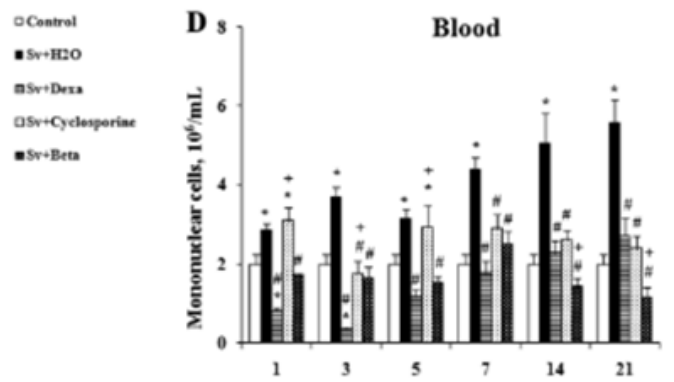

$\mathbf{E}$
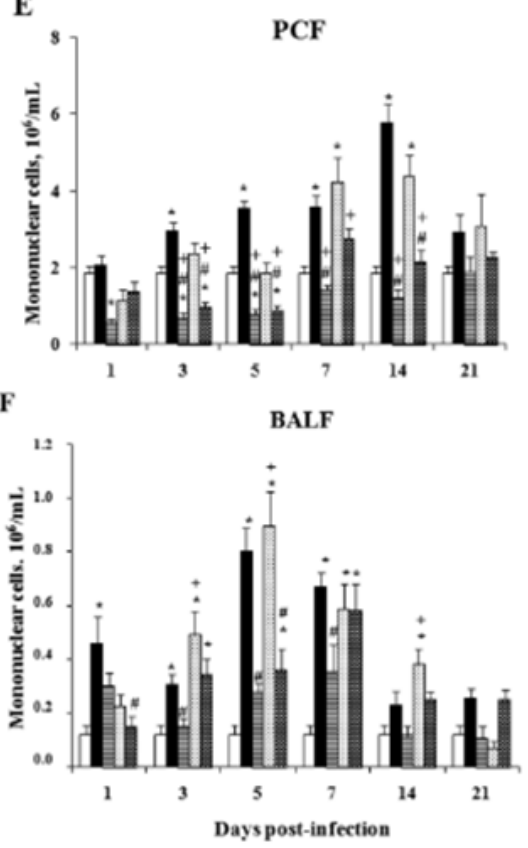

Figure 4 Number of eosinophils $(A-C)$ and mononuclear cells $(D-F)$ found in the blood (A and D), PCF (B and E), and BALF (C and F) of mice infected with $S$.

venezuelensis (Sv) larvae cultured for 3 days at $28^{\circ} \mathrm{C}$ and treated or untreated daily per s.c. with Dexa, dexamethasone; CsA, cyclosporine; Beta, betamethasone. A group of uninfected mice was used as a control. Data are expressed as the mean $\pm S E M$ from 2 independent experiments $(n=6-10 /$ day), uninfected animals $(n=6-7 /$ day). Statistical comparisons were made within each particular day of infection. *, Controls vs. $\mathrm{Sv}+\mathrm{H}_{2} \mathrm{O}, \mathrm{Sv}+\mathrm{Dexa}, \mathrm{Sv}+\mathrm{CsA}$, or Sv+Beta; ${ }^{\#} \mathrm{~S} v+\mathrm{H}_{2} \mathrm{O} ;{ }^{\&} S_{v}+$ Dexa; +CsA; ${ }^{\phi} \mathrm{S} v+$ Beta. ${ }^{*}+\phi \mathrm{P}<0.05$.

Beta treatment also appeared to decrease the influx of total leucocytes, eosinophils and mononuclear cells in the BALF, however, the inhibition induced by this drug was lower than that induced by Dexa. The CsA treatment appeared to interfir much less in the total leucocyte, eosinophil and mononuclear cell recruitment to lungs of S. venezuelensis-infected mice.

\section{Discussion}

The glucocorticoids Dexamethasone (Dexa), Betamethasone together with Cyclosporine (CsA) are used to suppress the inflammation or immune response in diseases like rheumatoid arthritis, renal diseases, hepatic diseases, allergies, asthma, colitis ulcerative, Crohn disease, organ transplant rejection, and AIDS. ${ }^{11,22-}$ ${ }^{24}$ In these treatments, Dexa, CsA or Beta can be used alone or in association to promote production, maturation, reduction and/or migration of inflammatory cells in transplanted organ thus decreasing rejection or the perpetuation of other inflammatory diseases. It is recognized, however, that while the imunossupression improves the condition of the patient it also facilitates the reactivation of chronic infections caused by fungii, helminths, protozoa and viruses that, if did not diagnosed quickly, can seriously threaten the life of the patient. Findings from the literature reveal situations of imunossupression of the cellular or humoral immune response using CsA alone or together with Dexa or Beta that have induced reactivation of latent diseases such as tuberculosis, ${ }^{25,26}$ Chagas' Disease, ${ }^{27,28}$ toxoplasmosis, ${ }^{29}$ and leishmaniasis.$^{30}$ Data of literature reported that patients with chronic strongyloidiasis, when treated with glucocorticoids administrated alone or together with CsA, manifested a dissemation of the strongyloidiasis. ${ }^{31,32}$

Patients with chronic strongyloidiasis who have been treated with CsA have suffered an activation of the infection and increased parasitism without, however, dissemination of the parasite. ${ }^{33}$ These results suggest that CsA probably produces some protective effects against strongyloidiasis. ${ }^{33} \mathrm{~A}$ number of cases of individuals that have experienced dissemination of the strongyloidiasis infection after administration of only one dose of glucocorticoids have been described in the literature. ${ }^{34}$ In many such cases there were fatalities, ${ }^{11,35}$

Helminth infections are associated with eosinophilia in the blood, cavity peritoneal and lung space. ${ }^{36}$ The results of the present study, using mice infected by S. venezuelensis, corroborate findings described in the literature explaining that human and experimental strongyloidiasis are characterized by systemic increases of inflammatory cells including eosinophils, neutrophils, mononuclear cells. ${ }^{36-39}$ and mast cells in many tissues. ${ }^{40}$ Our research also concurred that during the infection by Strongyloides sp an increase occurs in the influx of inflammatory cells to the peritoneal cavity and the lungs. ${ }^{6}$

In our study, S. venezuelensis infected mice treated with Dexa, Beta and CsA demonstrated inhibited total leucocyte numbers during the entire course of infection. This inhibition, however, exhibited variations in all of the groups examined. Nevertheless it was clear that the Dexa treatment was more effective in inhibiting the production and release of these cells in the blood and migration to the peritoneal cavity and pulmonary space. These results suggest that the fluctuations of total leucocytes were associated with the variations of specific cells such as eosinophils, neutrophils and mononuclear cells. A notable inhibition of eosinophils and mononuclear cells was observed not only in blood but also in the peritoneal cavity and lung space.

The results from all groups experienced increased neutrophil cells in the blood, however these cells was not recruited to the peritoneal cavity or pulmonary space. Among the three drugs administrated, Dexa was found to be superior in providing a synthesis of neutrophils during the infection and after the treatment. The neutrophilia observed has also been reported in the literature..$^{41,42}$ In these articles, the authors explain that glucocorticoids increase the anti inflammatory transcription of proteins such as lipocortina-1; IL-10, IL-1R2, ${ }^{24}$ reducing the apoptosis and increasing the Neutrophil survival. ${ }^{24,43}$

Research involving various hosts infected with helminths has revealed that treatment with glucocorticoids can produce significant reduction in inflammatory cells. Among the efforts reported in this area: Nippostrongylus brasiliensis in rats and mice, ${ }^{44}$ Schistosoma mansoni in mice, ${ }^{45,46}$ Echinostoma caprini and Echinostoma trivolvis 
in hamsters and mice, ${ }^{47}$ Trichostrongylus colubriformis in gerbils, ${ }^{48}$ and Strongyloides stercoralis in humans. ${ }^{34}$ The authors report that hosts treated with Dexa, CsA and Beta experienced significant inhibition in inflammatory cells and this cellular imunossupression favored and increased the permanence of the parasites in the host, and increasing also the fertility of the adult parasites. These results demonstrated by the high quantity of eggs, and larvae expelled in the feces or maintained in the different organs. Data from the present study are in agreement with data described in the literature, ${ }^{44-48}$ the number of adult females, eggs and infective larvae recovered from the infected mice that had been treated with Dexa, Beta and/or CsA were significantly higher than found in the infected and untreated mice. Additionally, the three drugs, due to the imunossupression, allowed more time for retention of the adult female parasites in the host.

The results suggest that the prolonged time of the parasitism in the host treated with CsA was due to cellular imunossupression induced by the drug, whereas the glucocorticoids Dexa and Beta not only increased the time of the parasitism due to imunossupression cellular but stimulated fertility, growth and maturation of the evaluative forms of $S$. venezuelensis. This fact was clearly demonstrated by the increased time of the intestinal parasitism, female fertility and larvae numbers recovered from the lungs during the process of observation.

Dexa, CsA and Beta constitute a powerful set of drugs used in the therapeutic intervention of several diseases, however, for individuals who present chronic strongyloidiasis, treatment with these drugs, principally with Dexa and Beta, can be life threatening. As these drugs increase the time of parasitism, due to imunossupression, and act as exogenous hormones stimulating growth and increasing the fertility of the female parasites, great quantities of eggs are produced. These findings suggests that glucocorticoids can improve fertility by adult parasites, rabditoid larvae to grow and transform into infective larvae and close the life cycle of the parasite, as described in the literature. ${ }^{18,49}$

The mechanisms involved in the process of activation and maintenance of the strongyloidiasis infection induced by glucocorticoids are still unknown. However, studies are being conducted by our group to evaluate these mechanisms. One hypothesis is that adult female parasites of Strongyloides sp present receptors for eicosanoids, cytokines, and chemokines in the cuticle. These receptors receive stimulii for reproduction and growth, disseminating the parasite. Another hypothesis is that hosts treated with glucocorticoids present an inhibition of the molecular and cellular components such as eosinophils, mononuclear cells, mast cells, neutrophils, cytokines and antibodies which contribute to the maintenance of the parasitism and favor dissemination. In conclusion, these results showed that glucocorticoid treatment induce disseminated strongyloidiasis while CsA appears to be positive in host defense against Strongyloides sp infection.

\section{Funding}

Fundação de Amparo à Pesquisa do Estado de São Paulo (FAPESP), Conselho Nacional de Desenvolvimento Científico e Tecnológico (CNPq), and the Coordenação de Aperfeiçoamento de Pessoal de Ensino Superior (CAPES).

\section{Acknowledgements}

This study was supported by the Fundação de Amparo à Pesquisa do Estado de São Paulo (FAPESP), the Conselho Nacional de Desenvolvimento Científico e Tecnológico (CNPq), and the
Coordenação de Aperfeiçoamento de Pessoal de Ensino Superior (CAPES). We are grateful to João B. A. Oliveira of the Laboratório de Parasitologia, Instituto de Biologia, Universidade Estadual de Campinas for his help with the maintenance and infection of the mice.

\section{Conflicts of interest}

Authors declare that there is no conflict of interest.

\section{References}

1. Grove DI. Human strongyloidiasis. Adv Parasitol. 1996;38:251-309.

2. Machicado JD, Marcos LA, Tello R, et al. Diagnosis of soil-transmitted helminthiasis in an Amazonic community of Peru using multiple diagnostic techniques. Trans R Soc Trop Med Hyg. 2012;106(6):333339

3. Salvador F, Treviño B, Bosch-Nicolau P, et al. Strongyloidiasis screening in migrants living in Spain: systematic review and meta-analysis. Trop Med Int Health. 2019;23.

4. Agrawal V, Agarwal T, Ghoshal UC. Intestinal strongyloidiasis: a diagnosis frequently missed in the tropics. Trans R Soc Trop Med Hyg. 2009;103(3):242-246.

5. Woodring JH, Halfhill H, Reed JC. Pulmonary strongyloidiasis: clinical and imaging features. Am $J$ Roentgenol. 1994;162(3):537-542.

6. Machado ER, Teixeira EM, Gonçalves-Pires MR, Loureiro ZM, Araújo RA et al. Parasitological and immunological diagnosis of Strongyloides stercoralis in patients with gastrointestinal cancer. Scand J Infect Dis. 2008;40(2):154-158.

7. Balagopal A, Mills L, Shah A, et al. Detection and treatment of Strongyloides hyperinfection syndrome following lung transplantation. Transpl Infect Dis. 2009;11(2):149-154.

8. Bava AJ, Troncoso AR. Strongyloides stercoralis hyperinfection in a patient with AIDS. $J$ Int Assoc Physicians AIDS Care (Chic). 2009;8(4):235-238.

9. Robson D, Welch E, Beeching NJ, et al. Consequences of captivity: health effects of far East imprisonment in World War II.QJM. 2009;102:87-96.

10. Wirk B, Wingard, JR. Strongyloides stercoralis hyperinfection in hematopoietic stem cell transplantation. Transpl Infect Dis. 2009;11(2):143-148.

11. Lim S, Katz K, Krajden S, et al. Complicated and fatal Strongyloides infection in Canadians: risk factors, diagnosis and management. CMAJ. 2004;175(5):479-484.

12. González-Posada JM, Hernández D, Martin A, et al. Hemophagocytic lymphohistiocytosis in a pancreas-kidney transplant recipient: response to dexamethasone and cyclosporine. Clin Nephrol. 2008;70(1):82-86.

13. Preynat-Seauve $\mathrm{O}$, de Rham $\mathrm{C}$, Tirefort $\mathrm{D}$, et al. Neural progenitors derived from human embryonic stem cells. $J$ Cell Mol Med. 2009;13:3556-3569.

14. Kahan BD. Cyclosporine. The New Engl J Med. 1989;321:1725-1738.

15. De Mattos AM, Olyaei AJ, Bennett WM. Pharmacology of immunosuppressive medications used in renal diseases and transplantation. Am J Kidney Dis. 1996;28(5):631-667.

16. Manna R, Verrecchia E, Fonnesu C, et al. Cyclosporine a: good response for patients affected by autoimmune disorders and HCV infection. Eur Rev Med Pharmacol Sci. 2009:63-69.

17. Shrestha R, Kharel Sitaula R, Karki P, et al. Combined Intravitreal Bevacizumab And Dexamethasone In Bilateral Lupus Retinopathy. Int Med Case Rep J. 2019;12:329-333. 
18. Genta RM. Dysregulation of strongyloidiasis: a new hypothesis. Clin Microbiol Reviews. 1992;5(4):345-355.

19. Machado ER, Ueta MT, Lourenço EV, et al. Infectivity of Strongyloides venezuelensis is influenced by variations in temperature and time of culture. Exp Parasitol. 2011;127(1):72-79.

20. Machado ER, Ueta MT, Lourenço EV, et al. Leukotrienes play a role in the control of parasite burden in murine strongyloidiasis. J Immun. 2005; 175(6):3892-3999.

21. Gordon HM, Whitlock HVA. New technique for counting nematode eggs in sheep feces. CSIR. 1939;12(1):50-52.

22. Berk SL, Verghese A. Parasitic pneumonia. Semin Respir Infect. 1988;3(2):172-178.

23. Mcgowan JEJr, Chesney PJ, Crossley KB, et al. Guidelines for the use of systemic glucocorticosteroids in the management of selected infections. Working Group on Steroid Use, Antimicrobial Agents Committee, Infectious Diseases Society of America. J Infect Dis. 1992;165(1):1-13.

24. Barnes PJ. Anti-inflammatory actions of glucocorticoids: molecular mechanisms. Clin Sci. 1998;94(6):557-572.

25. Molenaar RP, Jansen CL, Taphoorn MJ. Three patients with tuberculous meningitis: treatment started at tentative diagnosis. Ned Tijdschr Geneeskd. 2008;152(11):593-598.

26. Sundaram M, Adhikary SD, John GT, et al. Tuberculosis in renal transplant recipients. Indian J Urol. 2008;24(3):396-400.

27. Marchiori PE, Alexandre PL, Britto N, et al. Late reactivation of Chagas disease presenting in a recipient as an expansive mass lesion in the brain after heart transplantation of chagasic myocardiopathy. J Heart and Lung Transpl. 2007;26(11):1091-1096.

28. Medeiros MB, Guerra JA, Lacerda MV. Meningoencephalitis in a patient with acute Chagas disease in the Brazilian Amazon. Rev Soc Bras Med Trop. 2008;41(5):520-521.

29. Takashima Y, Suzuki K, Xuan X, et al. Detection of the initial site of Toxoplasma gondii reactivation in brain tissue. Int J Parasitol. 2008;38(5):601-607.

30. Levy L, Nasereddin A, Rav-Acha M, et al. Prolonged fever, hepatosplenomegaly, and pancytopenia in a 46-year-old woman. PLoS Med. 2009;6(4): 1000053 .

31. Palau LA, Pankey GA. Strongyloides hyperinfection in a renal transplant recipient receiving cyclosporine: possible Strongyloides stercoralis transmission by kidney transplant. Am J Trop Med Hyg. 1997;57(4):413-415.

32. Rodrigues MA, Froes RC, Anefalos A, et al. Invasive enteritis by Strongyloides stercoralis presenting as acute abdominal distress under corticosteroid therapy. Rev Hosp Clin Facul Med Sao Paulo. 2001;56(4):103-106.

33. Said T, Nampoory MR, Nair MP, et al. Hyperinfection strongyloidiasis an anticipated outbreak in kidney transplant recipients in Kuwait. Transpl Proceed. 2007;39(4):1014-1015.
34. Thomas MC, Costello SA. Disseminated strongyloidiasis arising from a single dose of dexamethasone before stereotactic radiosurgery. Int J Clin Pract. 1998;52(7):520-521.

35. Kia EB, Rahimi HR, Mirhendi H, et al. A case of fatal strongyloidiasis in a patient with chronic lymphocytic leukemia and molecular characterization of the isolate. Korean J Parasitol. 2008;46(4):261-263.

36. Lambroza A, Dannenberg AJ. Eosinophilic ascites due to hyperinfection with Strongyloides stercoralis. Amer J Gastro. 1991;86(1):89-91.

37. Mir A, Benahmed D, Igual R, et al. Eosinophil-selective mediators in human strongyloidiasis. Parasite Immunol. 2006;28(8):397-400.

38. Padigel UM, Stein L, Redding K, et al. Signaling through Galphai2 protein is required for recruitment of neutrophils for antibody-mediated elimination of larval Strongyloides stercoralis in mice. J Leukoc Biol. 2007;81(4):1120-1126.

39. Machado ER, Carlos D, Lourenço EV, et al. Counterregulation of Th2 immunity by interleukin 12 reduces host defenses against Strongyloides venezuelensis infection. Microb Infect. 2009;11(5):571-578.

40. Tegoshi T, Okada M, Nishida M, et al. Early increase of gut intraepitelial mast cell precursors following Strongyloides venezuelensis infection in mice. Parasitology. 1997;114:181-187.

41. Thanasak J, Jorritsma R, Heok A, et al. The effects of a single injection of dexamethasone-21-isonicotinate on the lymphocyte functions of dairy cows at two weeks post partum. Vet Res. 2004;35(1):103-112.

42. Weber PS, Toelboell T, Chang LC, et al. Mechanisms of glucocorticoidinduced down-regulation of neutrophil L-selectin in cattle: evidence for effects at the gene-expression level and primarily on blood neutrophils. J Leukoc Biol. 2004;75(5):815-827.

43. Cox G. Glucocorticoid treatment inhibits apoptosis in human neutrophils. J Immunol. 1995;154(9):4719-4725.

44. Ishikawa N. Histochemical characteristics of the globet cells mucins and their roles in defence mechanisms against Nippostrongylus brasiliensis infection in the small intestine of mice. Paras Immun. 1994;16(12):649654.

45. Hermeto MV, Bicalho RS, da Silva RE, et al. Oogram studies in mice infected with Schistosoma mansoni and treated with dexamethasone. Rev Inst Med Tropi São Paulo. 1994;36(2):99-104.

46. Pyrrho AS, Ramos JÁ, Neto RM, et al. Dexamethasone, a drug for attenuation of Schistosoma mansoni infection morbidity. Antimicrob Agents Chemother. 2002;46(11):3490-3498.

47. McMaster RP, Huffman JE, Fried B. The effect of dexamethasone on the course of Echinostoma caproni and E. Trivolvis infections in the golden hamster (Mesocricetus auratus). Parasit Res. 1995;81(6):518-521.

48. Ziam H, Pandey VS, Darwiche J, et al. Biological parameters of Trichostrongylus colubriformis in Meriones unguiculatus. Vet Parasitol. 1999;81(4):309-322.

49. Tam J, Schwartz KL, Keystone J, et al. Case Report: Central Nervous System Strongyloidiasis: Two Cases Diagnosed Antemortem. Am J Trop Med Hyg. 2019;100(1):130-134. 